\section{The spacesuit unpicked}

Margaret Weitekamp reflects on how fashion influenced astronautical attire for the Apollo missions.
W

hen Neil Armstrong took "one small step" on to the Moon's surface in 1969, his soft, white, layered spacesuit insulated, cooled, pressurwhat many people had thought he would be wearing. Most engineers imagined lunar landing suits as hard, man-shaped, jointed shells containing pressurized environments - essentially, individual ambulatory spacecraft. The iconic suit, known as the A7L and designed by the International Latex Corporation (ILC) then in Dover, Delaware, accomplished the same task with carefully stitched rubberized or reinforced, each was chosen to impart flexibility, strength, insulation or protection without excessive weight or bulk.

Using the 21 layers of the A7L as his inspiration, in the same number of chapters, architect Nicholas De Monchaux considers the social, cultural and political contexts of the iconic suit. He sees the hand-crafted garment as an essential counterpoint to today's prevailing emphasis on systems, so common ized and protected his body. But it was not layers of innovative materials. Synthetic,

\section{DNATURE.COM}

For more on conserving NASA's spacesuits: go.nature.com//udsdmi in engineering, architecture and design. Systems thinking considers humans as one factor in a broad engineering schema rather than dealing with humanity's complexity and variability, de Monchaux argues. He contends that such abstract thinking is not adaptable enough to master the realities of human life, at any scale. Instead, he suggests that the Apollo spacesuit offers a model for creating complex, responsive designs for other human environments, such as cities on Earth - "our only enduring spaceship".

Unlike many other books on the space race, Spacesuit connects the technical story with the broader history of the period, linking fashion with the military-industrial complex. De Monchaux includes the expected histories of high-altitude ballooning and its perils (including hypoxia and the bends), the development of partial- and

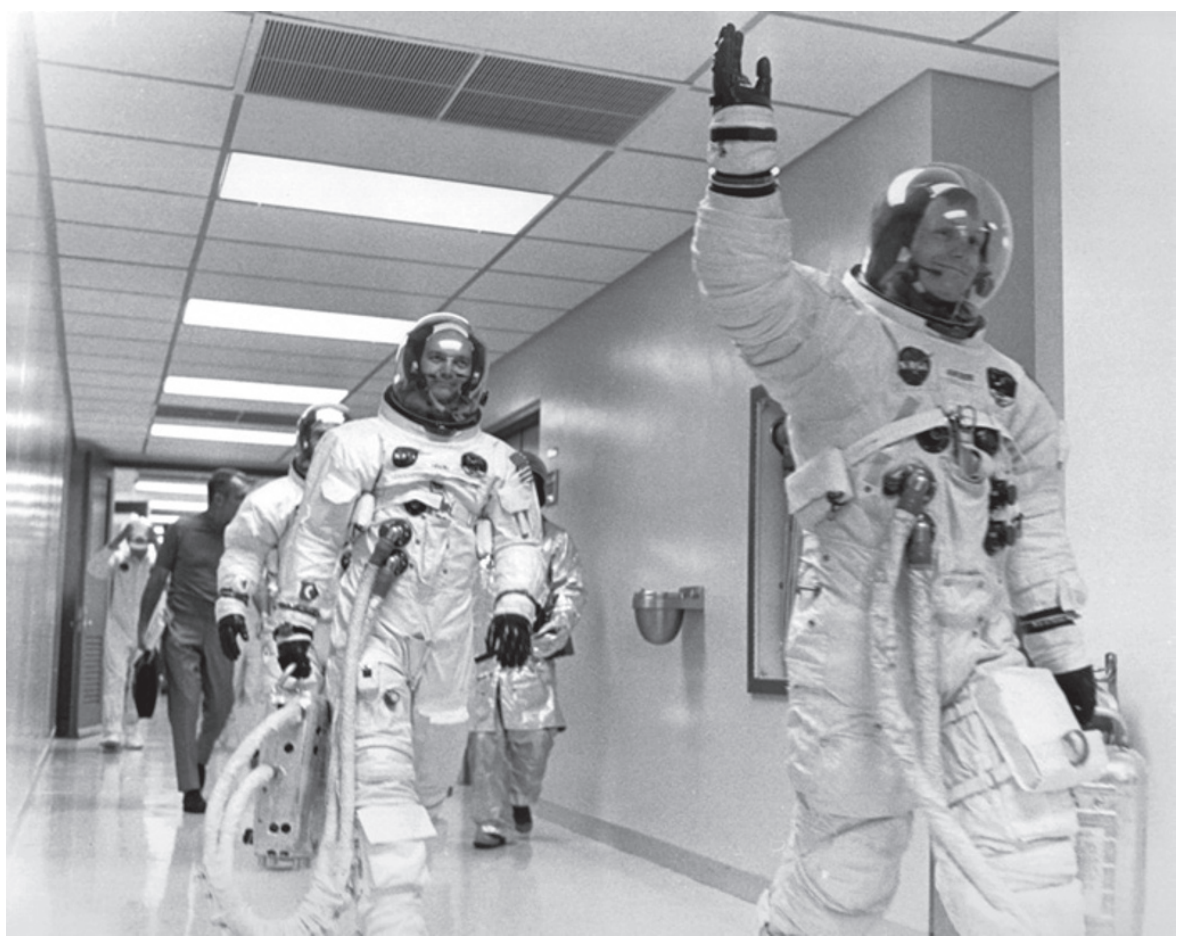

Buzz Aldrin (left, just seen), Michael Collins and Neil Armstrong wore hand-stitched A7L suits for Apollo 11. full-pressure suits and the experiments of early aeromedical researchers. But he also weaves in Christian Dior's New Look.

Dior's extravagant dresses of 1947 electrified the postwar world with their full skirts that, in contrast to those made during wartime fabric rationing, used many yards of fabric. 'New Look' became shorthand for describing sweeping changes in fields as diverse as plastics, criminal justice, roads and politics. De Monchaux unites these diverse topics through his analysis of the 'new look' in defence planning, a concept that drove changes in postwar agencies such as NASA.

It is at the core of the story, however, that Spacesuit gets most interesting - and most controversial. Those who know the history of NASA's spacesuit contracts will bristle at de Monchaux's conflation of the ILC and Playtex, maker of bras and girdles. In 1947, the materials company ILC split into four divisions. One was Playtex. But it was another division that, in 1962, became a subcontractor to Connecticut-based Hamilton Standard on a project to create a lunar space suit.

That the book pays little attention to other aerospace corporations working on spacesuits, including Hamilton Standard and the David Clark Company of Worcester, Massachusetts, will also irk some readers. With much personal and corporate pride still tied up with the production of these famous suits, Spacesuit will be seen as taking sides. But de Monchaux's book is not intended to be the authoritative history of spacesuit contracts. For that, see Kenneth Thomas and Harold McMann's US Spacesuits (Praxis, 2005), which excels in details but lacks readability.

De Monchaux has an ear for a good story and affection for the historical characters. In 1967, after the Apollo 1 cabin fire that killed three astronauts, NASA revisited its spacesuit contracts. In response to the new call for proposals, the ILC's soft suit design won a fierce competition to be the Apollo programme's Moon-walking suit. De Monchaux frames it as a David versus Goliath story, in which the "hard-knocks" engineers of the upstart ILC dug deep to outperform the aerospace behemoths. Through trials that included playing American football in the suit, the ILC garment's flexibility, compactness and durability won the day. Spacesuit offers a broad and creative appraisal of that suit's many contexts, encouraging readers to consider technology as design, shaped by the circumstances of its time, unfailingly and elegantly layered and crafted to serve a purpose.

Margaret A. Weitekamp is curator of the social and cultural dimensions of spaceflight at the National Air and Space Museum, Smithsonian Institution, Washington DC, USA.

e-mail:weitekampm@si.edu 